\title{
Construcción de hábitats sustentables en paisajes transformados de borde. Caso: Quiba-Arborizadora Alta, Bogotá-Colombia
}

\author{
Mayerling Sanabria Buitrago
}

Afiliación: Universidad de la Salle,Bogotá, Colombia

Email: msanabria@unisalle.edu.co

Recibido: 28 de agosto del 2017

Aceptado: 13 de noviembre del 2017

\section{Mayerling Sanabria Buitrago}

Ingeniera Ambiental y Sanitaria de la Universidad de la Salle. Mágister en Hábitat de la Universidad Nacional de Colombia. Actualmente labora como profesora investigadora al programa de Ingeniería Ambiental y Sanitaria de la Universidad de la Salle (Bogotá-Colombia).

\begin{abstract}
Resumen
La investigación que da pie a este artículo se basa en el estudio de los modos de habitar en zonas de borde sometidas a notables transformaciones de paisaje. Esto con el fin de reconocer la viabilidad sistémica de un espacio de transición urbano-rural usando como herramienta metodológica un modelo relacional conceptual que permita identificar la complejidad de su situación. Con dicha implementación se pretende identificar de manera directa y ágil oportunidades alternas de intervención en este tipo de entornos que promuevan la construcción de hábitats de borde sustentable. En este proceso se describirá, entonces, un contexto particular de ocupación y uso del territorio en el sector Quiba-Arborizadora Alta, en la localidad de Ciudad Bolívar en Bogotá, Colombia; donde, con la ayuda de un modelo dinámico conceptual semi-cuantificado, se identificaron aquellas relaciones que se establecen de manera cotidiana en este sector de borde. Con dicho modelo se pudo señalar la posible tendencia de dicho paisaje complejo frente a cambios inducidos, lo que permitió distinguir aquellas acciones que fomentarían efectivamente cambios sustanciales hacia la sustentabilidad de las áreas de borde en grandes centros urbanos como la Ciudad de Bogotá.
\end{abstract}

Palabras Clave: áreas de borde; hábitat; modelos sistémicos; paisaje; sustentabilidad.

Construction of Sustainable Habitats in Transformed Boundary Areas: Case: Quiba-Arborizadora Alta, Bogotá-Colombia

\begin{abstract}
The investigation this article is founded on is based on the study of the manners of living in boundary areas under the influence of landscape transformations. This was done aiming to identify the systemic feasibility of a space of rural-urban transition, using a conceptual relational model as a methodological tool that would allow to clarify the complexity of the situation. With such an implementation, it is meant to identify, in a direct and effective manner, the alternative opportunities of intervention in this kind of environment, promoting the creation of sustainable boundary areas. Because of this, the Quiba-Arborizadora Alta, in Ciudad Bolívar, Bogotá, Colombia, will be described as a particular context of occupation and use of the territory, where, with the use of a semi-quantified conceptual dynamic model, the relationships established everyday in this edge territory were identified. With this model, it was possible to point out the possible tendency of this complex landscape against induced changes, which allowed to distinguish the actions that would favor substantial changes for the creation of sustainable boundary areas in big urban centers, like Ciudad de Bogotá.
\end{abstract}

Keywords: boundary areas; habitat; landscape; system models; sustainability. 


\section{Introducción}

A

bordar los fenómenos de transformación que presentan las grandes ciudades en los bordes es estudiar de manera categórica las relaciones entre las personas y los lugares que habitan, pues es precisamente desde los territorios de borde donde se perciben de manera más directa los modelos de intervención de los sistemas naturales y la misma evolución urbana.

Actualmente, las dinámicas que se presentan en las periferias son procesos tan activos y poco sustentables que para la mayoría de las ciudades iberoamericanas el crecimiento de los bordes se plantea como una de las problemáticas urbanas más importantes en el desarrollo de las ciudades. Tal vez por esta razón, el estudio de las periferias urbanas ha evolucionado y ha dejado de enfocarse desde la planeación bajo un concepto netamente geográfico de ordenación espacial para incorporar una dimensión social y cultural, donde se reconoce que las formas de organización son las que determinan, finalmente, la sustentabilidad de dichos territorios.

Al considerar los bordes como espacios donde se concentran dinámicas particulares de ocupación, y que dependiendo de cómo se aborden podrían generar logros importantes en el mejoramiento de la transición urbano-rural, su productividad y la calidad de vida de sus habitantes, se propone con esta investigación el estudio sistémico de los modos de habitar en el sector Quiba-Arborizadora, al sur de Bogotá, de manera que se pueda identificar bajo un modelo relacional la tendencia del sistema en general. Para su cumplimiento, se desarrollaron tres fases: (i) el análisis de la situación particular de borde en Quiba-Arborizadora, donde inicialmente se reconoció el contexto de paisaje a través de las diferentes caracterizaciones y diagnósticos adelantados en el área; (ii) el estudio de las relaciones dinámicas entre los actores que inciden en la ocupación de dicho territorio, estableciendo su influencia en los procesos de transformación que presenta el paisaje actual; $y$ finalmente, (iii) el análisis del comportamiento del sistema bajo un modelo dinámico semi-cuantificado diseñado en el programa STELLA®, con el cual fue posible explorar la influencia de cada una de las variables que a lo largo de la investigación fueron incorporadas y convergieron como elementos constituyentes del referido modelo. Al final, bajo un ejercicio de modelación simple, se pudo identificar el cambio global del sistema frente al fortalecimiento o mitigación de las variables que lo componen.

En esta investigación se formula un concepto integral de paisaje bajo un análisis documental conciso, pues si bien el paisaje es reconocido coloquialmente como aquel terreno valorado por su aspecto escenográfico, esta definición no deja de ser una percepción simple y visual, donde se estima solo la parte estética del territorio; por el contrario, se intentó perfilar un concepto de paisaje en "clave de hábitat", donde se abordan otras dimensiones que contribuyen a su cambio y evolución.

Desde esta perspectiva, las adaptaciones humanas se consideran como contribuciones contundentes y propias de la evolución de los mismos paisajes, pues la configuración actual de cualquiera de ellos ha sido generada precisamente por las prácticas sociales y culturales que en él se despliegan; es decir, los modos de apropiación que las personas hacen de sus espacios (los mismos hábitos e intereses comunes) van creando tejidos de significaciones tan propios que son estos los que van modelando los cambios y transformaciones en el paisaje.

Es así que el concepto de paisaje no es posible de plantear sin los habitantes y su influencia cultural como un componente fundamental. Pues desde lo sistémico, es necesario integrar tanto la parte física (el territorio), como los diferentes actores que intervienen e influyen en su evolución hacia un hábitat humano (los actores).

1 Transformaciones no solamente desde el punto de vista de los impactos negativos por degradación de un espacio natural, sino referidas a la posibilidad de reconocer entre lo social, lo cultural y el espacio físico que se habita, eventos alternos o situaciones poco evidentes que puedan orientar una transición urbano-rural más sustentable en este borde tan particularmente caótico en Bogotá.
El sector de Quiba-Arborizadora ofrece toda una gama de situaciones por explorar que contribuirán al interés planteado en esta investigación respecto a: (i) evidenciar las relaciones entre el consumo de los recursos naturales, el valor ecosistémico de la región y el sentido de territorialidad de sus habitantes; y (ii) al reconocimiento de la influencia de las prácticas sociales y culturales en las transformaciones físicas de estos territorios de borde ${ }^{1}$. 
Figura 1. Localización general del área de estudio en Ciudad Bolívar, Sector Quiba-Arborizadora. Elaboración propia.

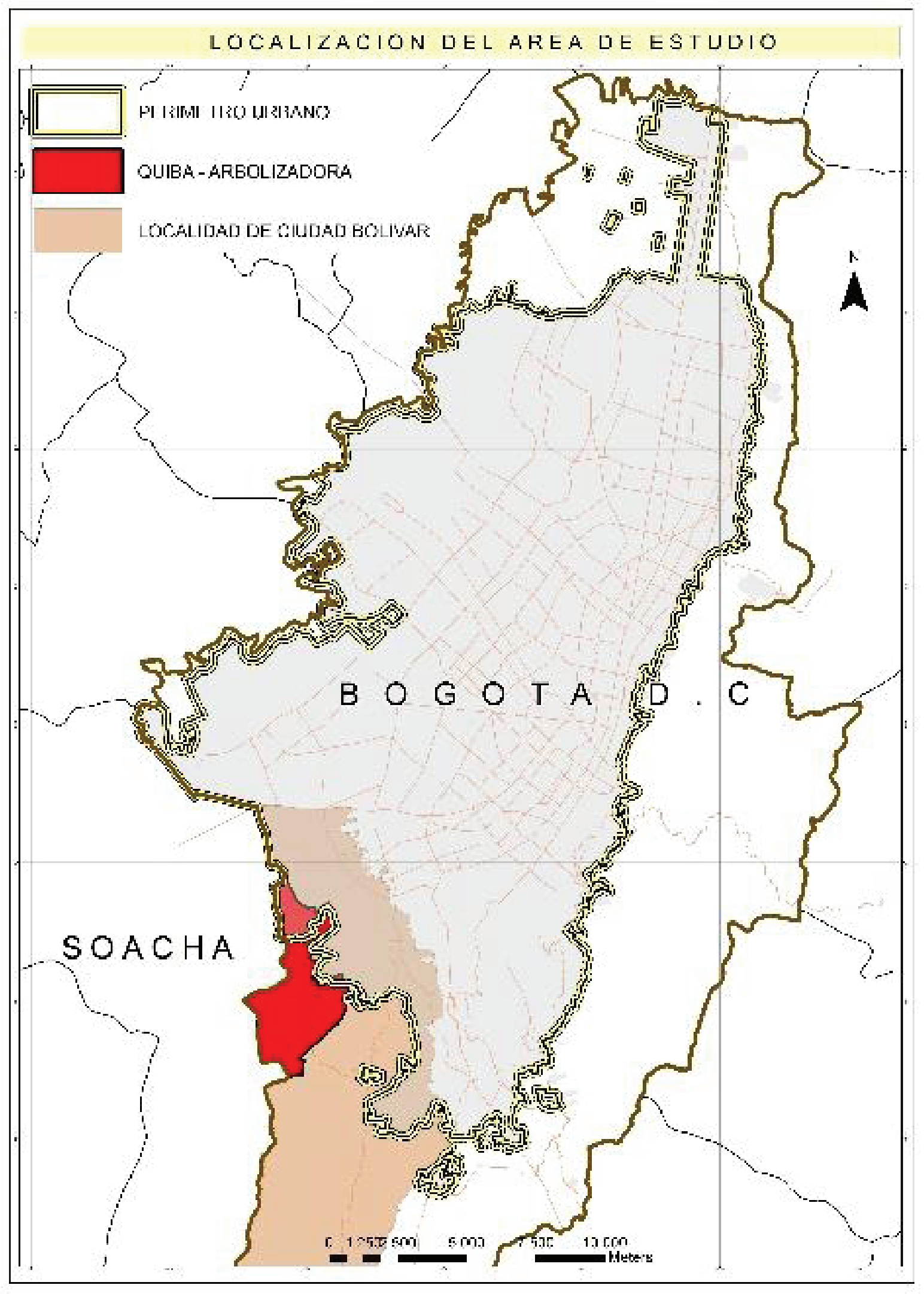

Situaciones como: minería(legal eilegal)porextracción de materiales parala construcción en áreas de ecosistemas estratégicos; falta de regulación del precio de la tierra; falta de oportunidades para el desarrollo rural integral; comunidades desplazadas; violencia; marginalidad; expansión urbana ilegal, entre otras, describen al contexto actual del área de estudio. Ante este panorama tan dinámico de transformación de paisaje, se hace necesario preguntarse ¿cómo identificar acciones que contribuyan a mejorar los modos de habitar en los bordes de ciudad sometidos a intensas transformaciones de su paisaje inicial?

Esta pregunta permite reconocer que, bajo un modelo relacional de enfoque sistémico, es posible comprender y descubrir aquellas acciones o conexiones que determinan el actual funcionamiento en los bordes de ciudad. Al caracterizar sistémicamente este territorio, se hacen evidentes diferentes dinámicas y relaciones que se manifiestan en el actual día a día, identificando estructuras y patrones que podrían modificarse para contribuir a una sostenibilidad futura. Es así que se diseñó y construyó un modelo

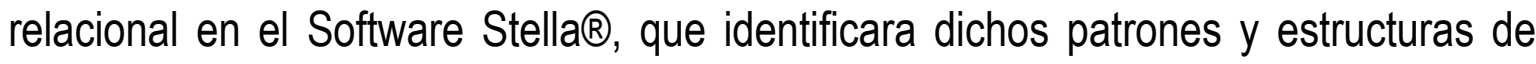
manera conjunta, permitiendo así una comprensión más completa de la realidad y no un análisis separado de sus componentes. 


\section{Referente teórico}

Evaluar, desde una perspectiva integral, la condición de deterioro progresivo que presenta actualmente el paisaje de las zonas de borde en Bogotá implica una precisión de los razonamientos teóricos y conceptuales abordados. A continuación, los más tratados:

\section{Hábitat / habitar: evidencias de la evolución simultánea de lo natural y lo cultural}

Si bien el concepto de hábitat fue acuñado inicialmente por las ciencias naturales para definir aquel espacio geográfico donde se establece una especie, se puede señalar, entonces, que dicho lugar representa las condiciones más favorables para que se desarrolle la vida; es decir, un territorio deseable. Y es bajo este precepto que se desea abordar el hábitat humano.

Según Echeverría (2009, p.34), el hábitat es aquel contenedor que bajo campos relacionales va construyendo dinámicamente escenarios de relaciones en donde cada componente contribuye a la compleja trama del habitar. Al respecto, Leff $(1997$, p.7) dice que el hábitat es la forma de inscripción de la cultura en un espacio geográfico, destacando, al igual que Echeverría, el acto de habitar; y si bien el hábitat implica también un espacio físico, este está permeado por una serie de simbolizaciones y significaciones, las cuales determinan usos y ocupaciones particulares.

Es evidente que, en el devenir del habitar, los territorios han sufrido alteraciones por la intervención antrópica, inicialmente como única alternativa para sobrevivir, y se percibe que dichas alteraciones están en pro de un desarrollo humano. Por eso, tal y como lo indica Leff (1997, p.10), "habitar es el proceso de renovación de la naturaleza desde identidades culturales diferenciadoras"; en otras palabras, el medio donde los seres humanos complejizan su existir, perfilándose así la cultura como un componente fundamental a la hora de comprender los modos de habitar.

En este sentido, sobre la caracterización de hábitat abordada por Sánchez $(2009$, p.6) en su artículo "El hábitat no es una cosa", vale la pena destacar la relación que identifica entre naturaleza, sociedad y habitante como componentes de un sistema dinámico, donde se reconoce que el hábitat no podría describirse de manera completa sin identificar los vínculos que relacionan cada uno de estos componentes; $y$ hace referencia también al hábitat como expresión simbólica del comportamiento humano; es decir, un reflejo de la expresión de las ideas, creencias y sentimientos, tanto individuales como colectivos, donde se vinculan las acciones y los sentimientos a las cosas mismas. Es así que el hábitat se percibe como un proceso en permanente evolución, un tejido complejo de relaciones y procesos dinámicos entre el ser humano con su entorno natural, regulados bajo una serie de conductas culturales intencionadas, enfocadas a la búsqueda del bienestar.

Teniendo en cuenta las referencias anteriores, sin duda, los modos de habitar se asocian con la manera enque se articulan los diversos factores y su función transformadora en el espacio físico (el territorio, y los que lo habitan) (ver figura 2), por lo que la cultura se vincula de manera directa, como indica Angel (1996, p.22): "la misma historia del hombre, no es posible comprenderla si no se considera como un proceso íntimamente vinculado a la transformación de su entorno".

Al entender la cultura como aquel conjunto de elementos físicos, sociales y simbólicos transmitidos por cada generación, donde no es posible reconocerla de manera aislada a la transformación del medio donde se desarrolla, se hace definitiva su influencia en la evolución de los paisajes, ya que no solamente debe incluirse la comprensión del espacio físico, sino también de los instrumentos de organización social y de cohesión simbólica de los que en él habitan. Por tanto, como una reflexión a resaltar, está el reconocimiento del componente cultural en la transformación del paisaje, ya que la evolución cultural es un hecho tan natural como la misma evolución biológica (Márquez, 2002, p.31). 
Figura 2. llustración de la relación entre los modos de habitar y el paisaje transformado habitado. Elaboración propia.

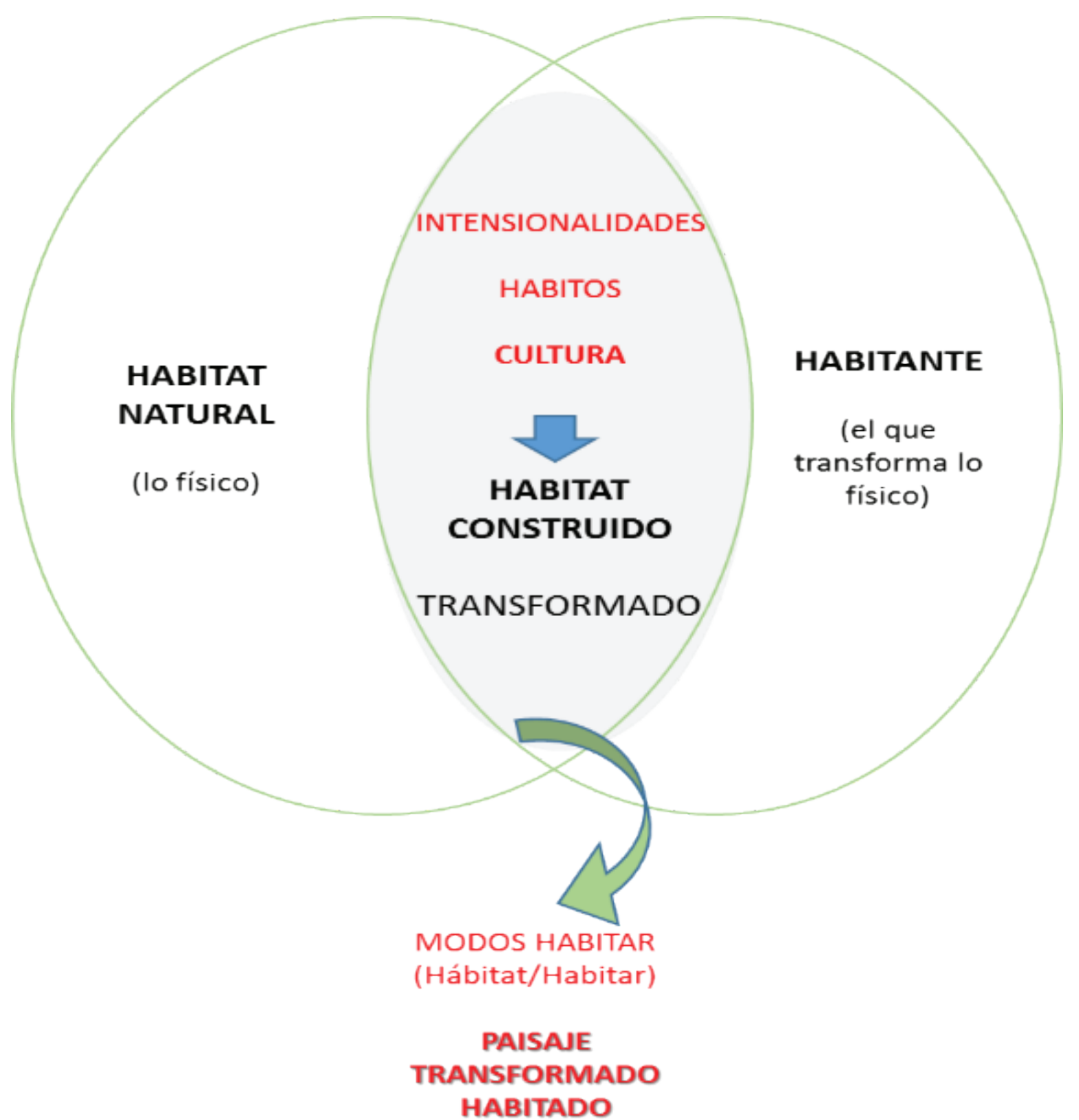

La evolución cultural, entonces, ha reflejado a través de la historia formas alternas de adaptación al medio (Márquez, 2002, p.14). Cada ser humano ha sido expuesto de manera diferente a procesos de acumulación cultural; es muy distinto cómo percibe el territorio una persona de la ruralidad a como lo hace una persona que habita en una gran metrópoli. En este sentido, la percepción del territorio estará dada por el capital cultural que cada individuo ha aprehendido a lo largo de su trayectoria.

Por tanto, la figura 2 sintetiza el concepto de "los modos de habitar". No es posible dividir el territorio físico de los que lo habitan y sus propios procesos culturales y sociales para conceptualizar sobre las formas de habitar. El ser humano es indivisiblemente un ser biológico y un ser social, pues es el resultado de los cambios físicos que percibe de su territorio, al igual que del aprendizaje social y herencias culturales del cual es parte, y de los que también evoluciona y se va transformando.

De acuerdo con esto, es posible reconocer entonces a "la cultura" como una estrategia adaptativa, es decir, si el medio también determina las formaciones culturales y la cultura a su vez modifica y determina la estructura y el funcionamiento del medio, es posible que, a través de formas organizativas alternas, se pueda mejorar dichas adaptaciones hacia modelos más sustentables, pues a través de la historia se reconoce que muchas sociedades han desaparecido al no haber establecido equilibrios estables con el medio.

\section{El paisaje bajo una visión sistémica de hábitat}

Abordar las relaciones entre el entorno y el que lo habita implica adoptar un enfoque sistémico en términos de conectividades, relaciones y contextos, pues según Capra $(1998$, p.46) las propiedades esenciales de un sistema son propiedades del todo que ninguna de las partes posee; es decir, son propiedades emergentes precisamente de las relaciones y conexiones que se manifiesten entre sus componentes en un espacio y un tiempo determinado. 
Figura 3. Esquema conceptual general de los modos de habitar. Elaboración propia.
Si bien el espacio es considerado el sustrato de la estructura de un sistema, que es en sí mismo delimitable (porque sin duda la existencia misma del sistema es física), solo es comprendido desde la experiencia perceptiva del observador, pues es observable para todos, pero cada uno, desde su propio enfoque. Por tanto, tal y como lo menciona Garciandía (2005, p.62), las fronteras de un sistema son un aspecto supeditado al observador y a ciertas condiciones de la observación. Es así como el espacio, el tiempo y el enfoque, determinan situaciones concretas pero transitorias de ocupación humana; es decir, se definen como una unidad flexible y variable, producto de la construcción social de un territorio donde se dan procesos de identidad y de sentido de pertenencia, pero también donde se presentan conflictos; todo esto, según la perspectiva del observador en un espacio/tiempo finito (Daza, 2006, p.22).

Justo desde el espacio/tiempo se permite comprender un contexto y la evolución que manifiesta a partir de sus construcciones sociales. En este sentido, un adecuado diagnóstico del paisaje se debe construir sobre la base del análisis de todos aquellos componentes que interactúan en un territorio, sin perder de vista su historia evolutiva y adaptativa que, en última instancia, son las que les confieren ciertas peculiaridades que permiten su diferenciación con respecto a otros lugares.

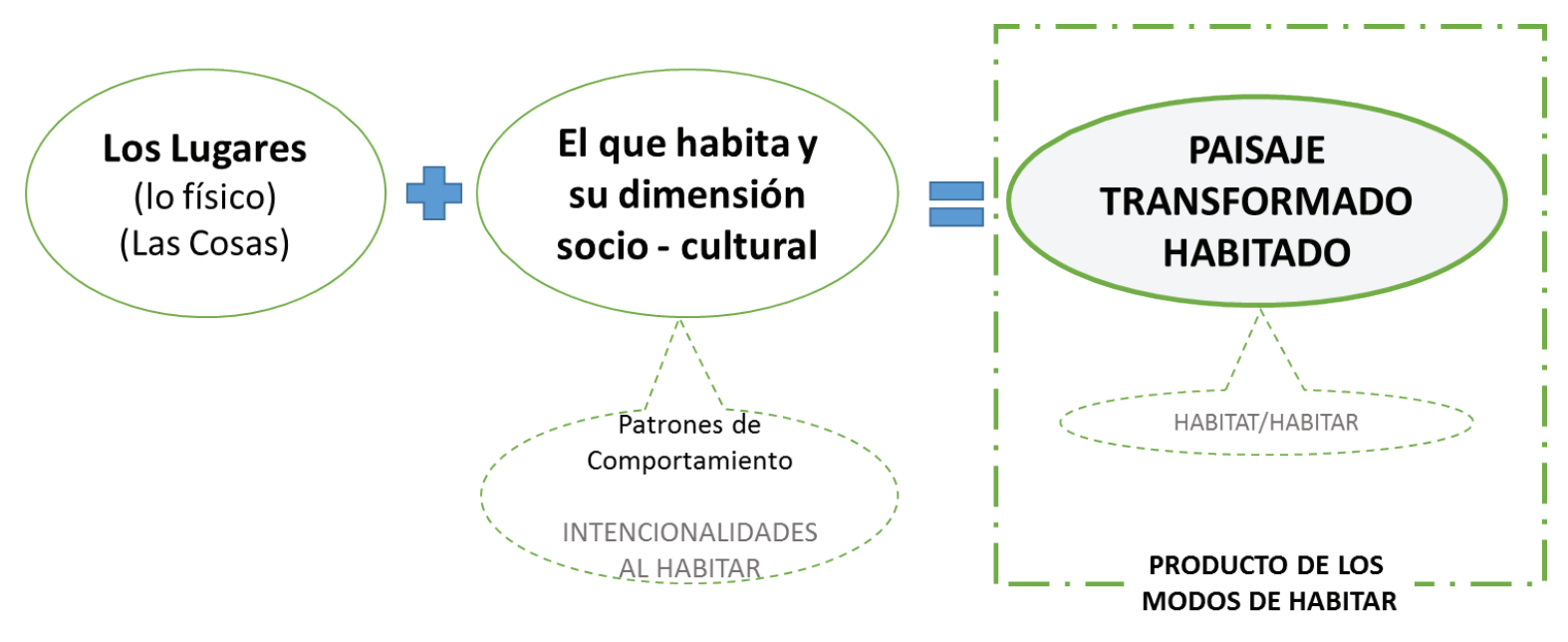

Bajo esta referencia, se puede esquematizar en la figura 3. La influencia del paisaje transformado (los modos de habitar), en un sentido más profundo, donde se evidencia la relación entorno / acciones humanas, en el que el entorno, más que representar todo aquello que rodea al ser humano, forma parte de él; es decir, se analiza el paisaje como aquel territorio donde el ser humano no se relaciona como la especie dominante, sino como un elemento más de la trama de la vida (Ángel, 1996, p.12). Sin duda, es un elemento muy importante, pues su impacto ha sido muy grande, más que el de cualquier otra especie, pero dichos impactos y transformaciones finalmente representan un producto en sí mismo de la evolución. Con esto, se puede decir que la gran diferencia entre el concepto de paisaje en las ciencias naturales y el que se aborda en esta investigación, se fundamenta precisamente en la inscripción del ser humano al sistema paisaje.

Bajo una contextualización sistémica, entonces, es posible conceptualizar que el paisaje es pues, la expresión de las interacciones complejas entre el ambiente, la sociedad, las percepciones propias del individuo frente a su territorio y sus propios patrones de comportamiento al habitar individual o colectivamente, tal como se expresa en la figura 4, donde se denota como los Modos de Habitar se asocian directamente con el paisaje transformado habitado.

Esta visión que se plantea bajo la teoría de los sistemas, es un pensamiento contextual que marca la interdependencia de lo que compone un sistema bajo un entretejido de eventos y fenómenos propios en un espacio/tiempo concreto, los cuales es posible comprender bajo modelos de redes a todo nivel; por tanto, comprender el paisaje de borde, es comprender las redes que se generan en él.

A partir del diagrama anterior (figura 4), es posible caracterizar de manera general la zona de Quiba-Arborizadora bajo los siguientes componentes:

- Sociedad/Habitante: Esquematizado como "los otros" y el "ser". Son los actores de manera individu al o colectiva. Para el área de estudio: 
Figura 4. Esquema de la construcción conceptual de los modos de habitar. Elaboración propia.

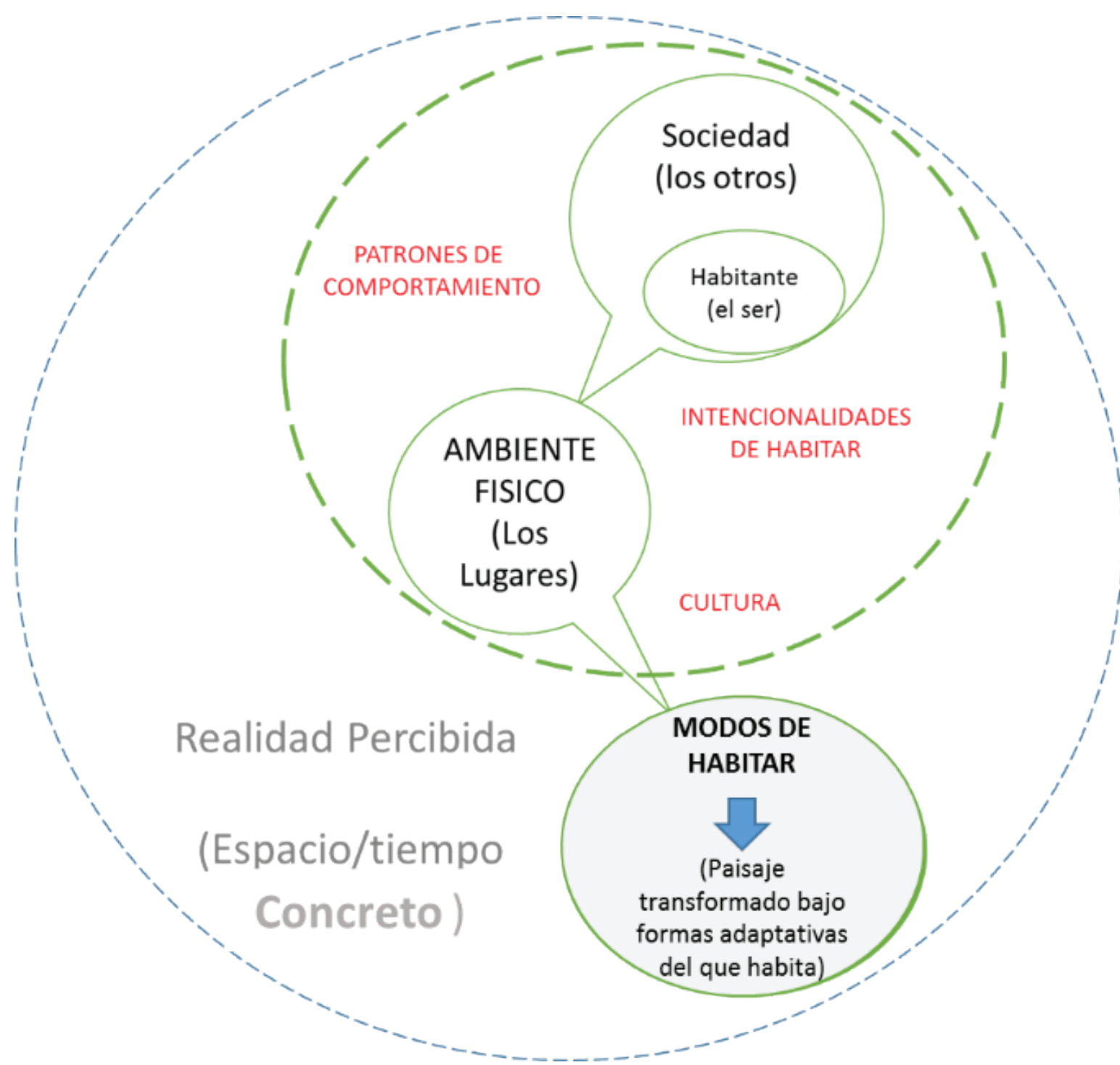

- Las comunidades de Borde: diferenciándose claramente la población rural campesina de los habitantes de la zona urbana del sector, donde la zona rural se caracteriza por ser predominantemente dispersa, y, por otro lado, el sector urbano que presenta una densa aglomeración en el borde.
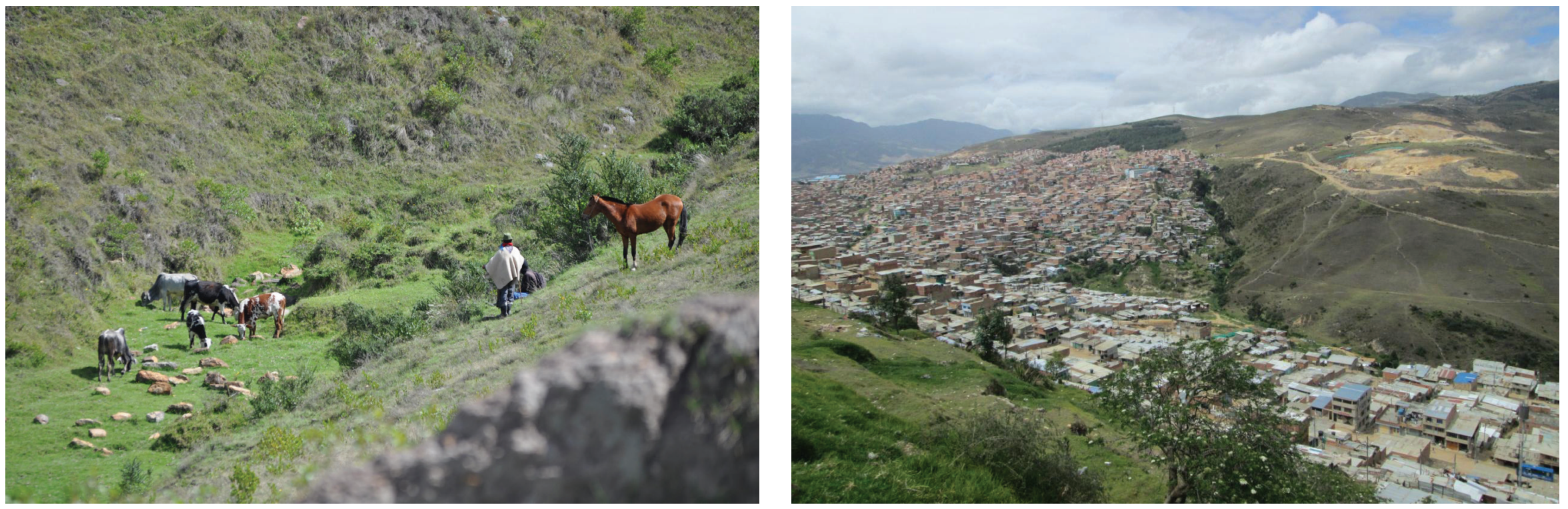

Figura 5 Actividades pecuaria en Quiba rural y Zona urbana de Arborizadora (Fotografías tomadas por el autor).
Esta clara diferenciación de uno y otro modelo de ocupación tiene unos antecedentes muy marcados respecto a su relación con el territorio y el reconocimiento de su hábitat. Las raíces colectivas, económicas, culturales y sociales propias de las comunidades rurales han regulado a través del tiempo el impacto de su desarrollo, mientras que la consolidación del proceso de urbanización en las zonas periféricas de la ciudad permite que se reconozcan como áreas en permanente conflicto entre los grupos sociales que allí conformados por familias desplazadas de las demás regiones del país.

- La Instituciones del estado: su fin es planificar y gestionar el desarrollo territorial de la ciudad y hacen presencia intermitente en el sector con programas de vivienda, cultura, educación, salud, ambiente, etc., los cuales obedecen a lineamientos e indicadores programados por la administración de turno que, en cierta medida, fundamenta su plan de desarrollo según las estrategias de inversión del gobierno nacional, así que la continuidad de procesos locales no es la prioridad. 
- La industria minera: se refiere a la extracción de materiales para la construcción. Esta zona se caracteriza por ser parte del único relicto de ecosistema subxerofítico de la región andina, que además se localiza en la formación coluvio-glaciar del río Tunjuelo, la cual es reconocida por su alto potencial de gravas, limos y arcillas, y no por su importancia en la regulación hídrica y climática de la región.
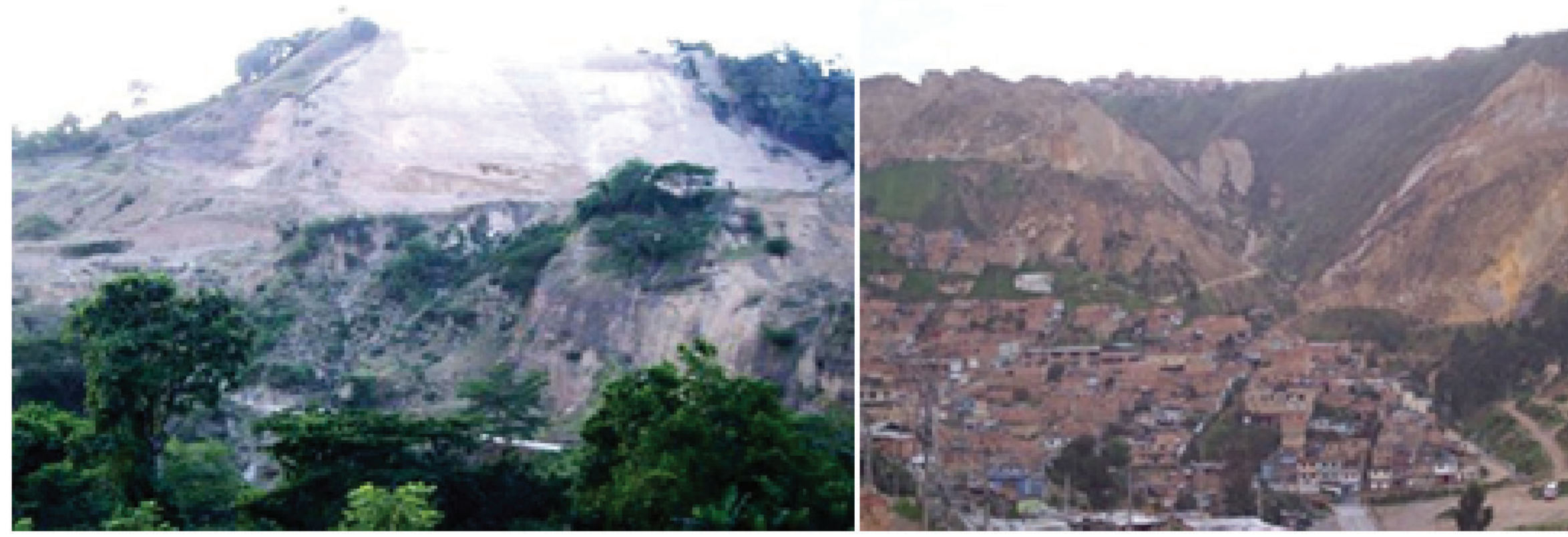

Figura 6. La industria minera en el área de estudio. Cortesía Secretaría Distrital de Ambiente.
- Las instituciones y saberes locales: Relacionados con las asociaciones comunitarias y el conocimiento tradicional que se han venido consolidando como iniciativas locales de participación en la ordenación de sus territorios. Desde las figuras de participación social identificadas en el área de estudio, Asamblea Sur, Consejo Consultivo del Sur, Mesa de Vida Digna y Territorio de Vida y Paz, tienen un reconocimiento importante por parte de la comunidad, y aunque intentan mantener continuidad en los procesos de participación que ellos mismos promocionan independientemente de la administración distrital de turno, reconocen que el respaldo institucional frente a sus propuestas de figuras de gestión comunitaria es la vía más efectiva de participación para la promoción de su desarrollo.

- Ambiente Físico: Este componente obedece claramente a la definición de Leff (2004, p.9), donde el ambiente actúa como el soporte donde se articulan los procesos físicos, biológicos, políticos, económicos y culturales, es decir, es aquel contenedor donde se desarrollan los modos de habitar. En este sentido, el "ser" y "los otros" referidos en la figura 4 son los directos transformadores de ese soporte estructural llamado Quiba-Arborizadora.

- Cultura: Finalmente, entre "los que transforman" y "el ambiente físico", la cultura se ratifica como el componente "modelador" del paisaje (ver figura 4), pues son las pautas de conducta individual o de un grupo social las que influyen de manera definitiva en la transformación de los territorios.

Al abordar la cultura como un componente importante del concepto de Paisaje Transformado Habitado (PTH), es necesario tener en cuenta la influencia de los patrones de comportamiento propios del ser humano y su relación con los otros, los cuales construyen sinergias que particularizan la manera como se modela y transforma el territorio.

En este sentido, Ángel (1996, p.43), en su libro "El Reto de la Vida, Ecosistema y Cultura", muestra cómo el Ecosistema y la Cultura emergen de la naturaleza; es decir, la misma cultura ha sido la plataforma que el hombre ha construido para poder adaptarse a la evolución natural que presentan los ecosistemas vivos, por lo que hay que considerar entonces a la cultura como una estrategia adaptativa de las estructuras sociales a su medio.

La especie humana es otro producto de la evolución, pero la capacidad de generar cultura es el rasgo distintivo de la humanidad frente a las demás especies vivas; y si muchos de los patrones culturales han sido heredados, pues entonces estos son susceptibles a cambios, es decir, podrían ser dirigidos hacia formas más sustentables 

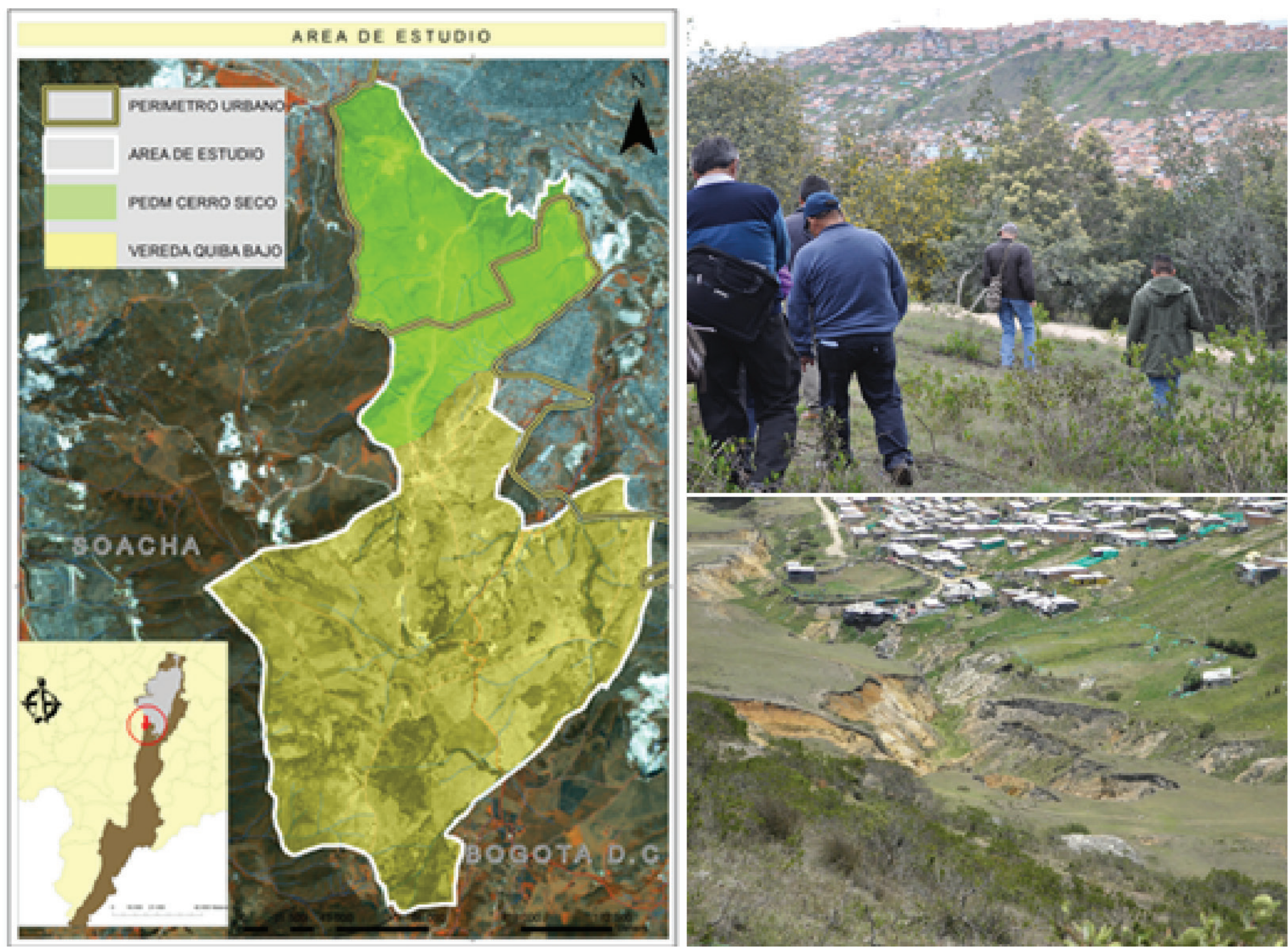

A

Figura 7. Transformación del paisaje del área de estudio. Fotografías tomadas por el autor.
Teniendo en cuenta lo anterior y retomando la trama de fenómenos interdependientes que se crean al relacionar los componentes de la figura 4, se aborda entonces el concepto de Paisaje Transformado Habitado (PTH) en la zona de Quiba-Arborizadora, pues es aquí donde se aprecia la manifestación pura de la evolución resultante entre la relación naturaleza-ser humano, bajo unas condiciones de espacio/tiempo específicas.

\section{Metodología}

Al considerar el sistema de Quiba-Arborizadora como un conjunto de situaciones y relaciones que conforman una unidad compleja, se pueden establecer conexiones entre dichos hechos que, al ser analizados bajo modelos dinámicos, permiten identificar el cambio del sistema a través del tiempo.

La simulación de modelos dinámicos a través de programas de computador permite estudiar el comportamiento de cualquier sistema complejo, pues aportan una visión más integral de la situación, lo cual contribuye finalmente a la toma de mejores decisiones. Es por esta razón que se incorporó como herramienta metodológica el programa STELLA® (Structural Thinking Experimental Learning Laboratory with Animation).

Cualquier comportamiento complejo del mundo real puede describirse y explicarse mediante sistemas de propiedades que forman estructuras de niveles y flujos articulados en bucles de realimentación (Forrester, 1994, p.4); estos diagramas representan gráficamente una estructura conceptual hipotética de cualquier modelo de realidad.

El programa Stella es considerado como uno de tantos métodos para el estudio del comportamiento de una situación real bajo unenfoque sistémico, mediantela construcción de modelos de simulación informática que ponen de manifiesto las relaciones entre la estructura del sistema y su organización bajo subsistemas relacionales (Morlan, 2010, p.38). 
Sin embargo, aun reconociendo las limitaciones que tendría la aplicación de cualquier programa de computador sobre aquellas representaciones de los fenómenos que ocurren en el mundo real (pues nunca atenderán la totalidad), este método representa una buena alternativa para acercarse a la comprensión global de los modos de habitar actuales en el área de estudio, por la dinámica de sistemas que aplica. Con el programa Stella, es posible representar bajo subsistemas situaciones presentes en QuibaArborizadora como patrones de relaciones entre los actores según sus actividades y funciones dentro de un espacio físico definido, lo que permite reconocer su organización, mantener su complejidad y facilitar su comprensión.

El programa maneja analogías entre los sistemas con la naturaleza, es decir, todo es flujos de información, niveles y/o variables conectadas entre sí. De esta manera, el programa Stella recrea una situación compleja bajo subsistemas conectados; cada uno de ellos está conformado por una serie de variables interconectadas e integradas bajo ecuaciones de diferencia que permiten evidenciar el cambio de "un proceso" entre lo que genera su incremento y aquello que aporta a su agotamiento (ver esquema de la figura 8).

Figura 8. Estructura principal del modelo Stella ${ }^{\circledR}$. Elaboración propia.

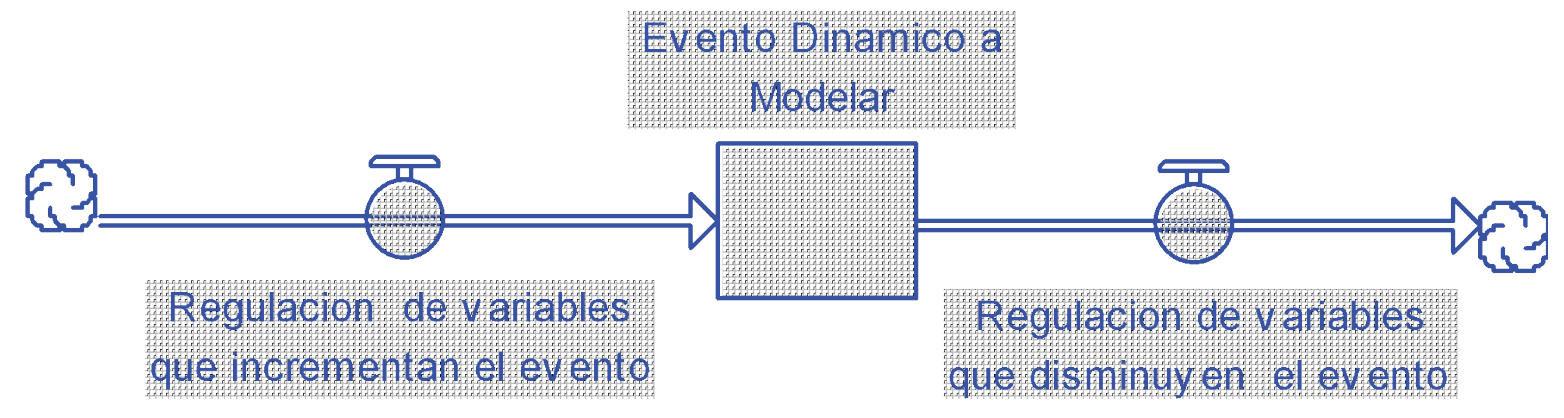

La aplicación de modelos formales como estos ayuda a entender el mundo y los fenómenos que en él ocurren de manera integral, al considerar las interrelaciones que suceden en él y no sólo el análisis de las partes que lo conforman (Murillo, 2007, p.28).

Del análisis de las condiciones del área de estudio, fueron adecuados al programa Stella 5 subsistemas con una relación de interdependencia tal que los hechos modelados describen aquellos procesos activos presentes en Quiba-Arborizadora. En la figura 9 se presentan conceptualmente los subsistemas implementados en el modelo, del cual se identifica como producto los modos de habitar de la zona de estudio:

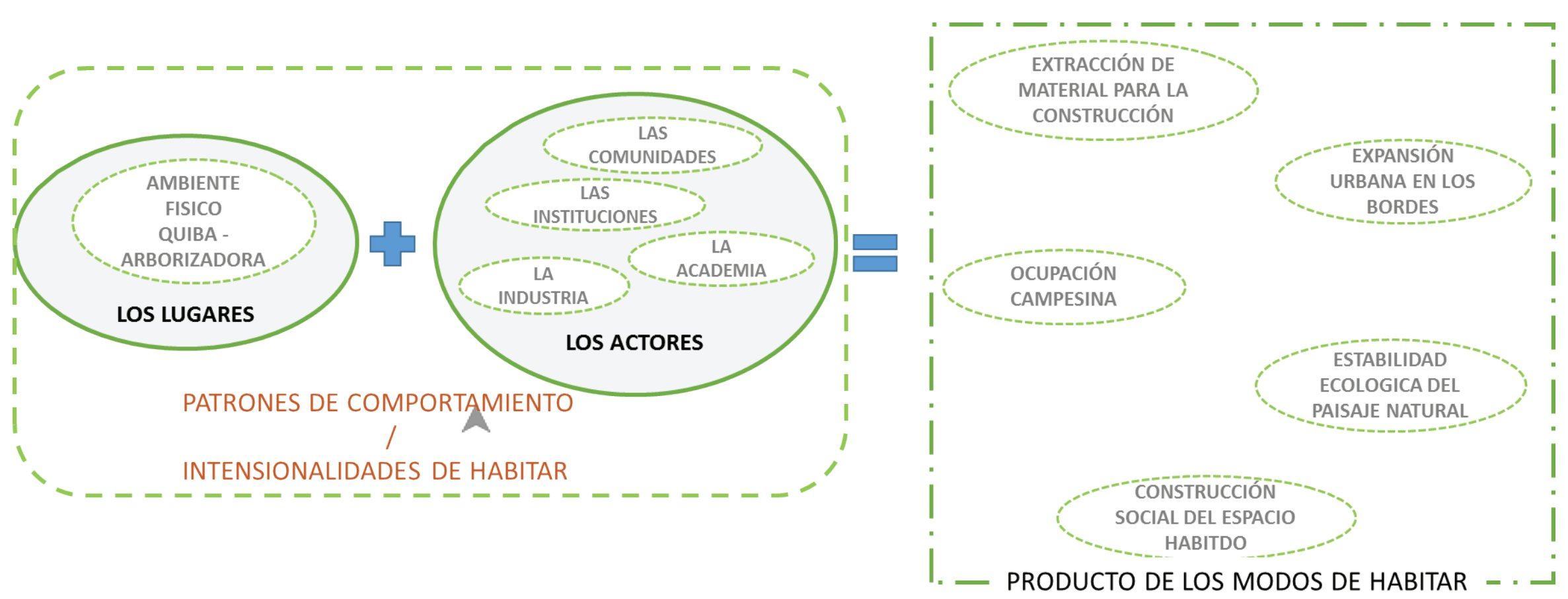

Figura 9. Esquema general de los modos de habitar en Quiba-Arborizador. Elaboración propia.
El diagrama anterior hace referencia a los modos de habitar más distintivos de la zona, que han sido categorizados como subsistemas y flujos de relaciones de la siguiente manera: 
Figura 10. Subsistemas relacionales de los modos de habitar en Quiba-Arborizadora. Elaboración propia.

Figura 11. Registro de Variables Identificadas para el subsistema ocupación campesina. Elaboración propia.

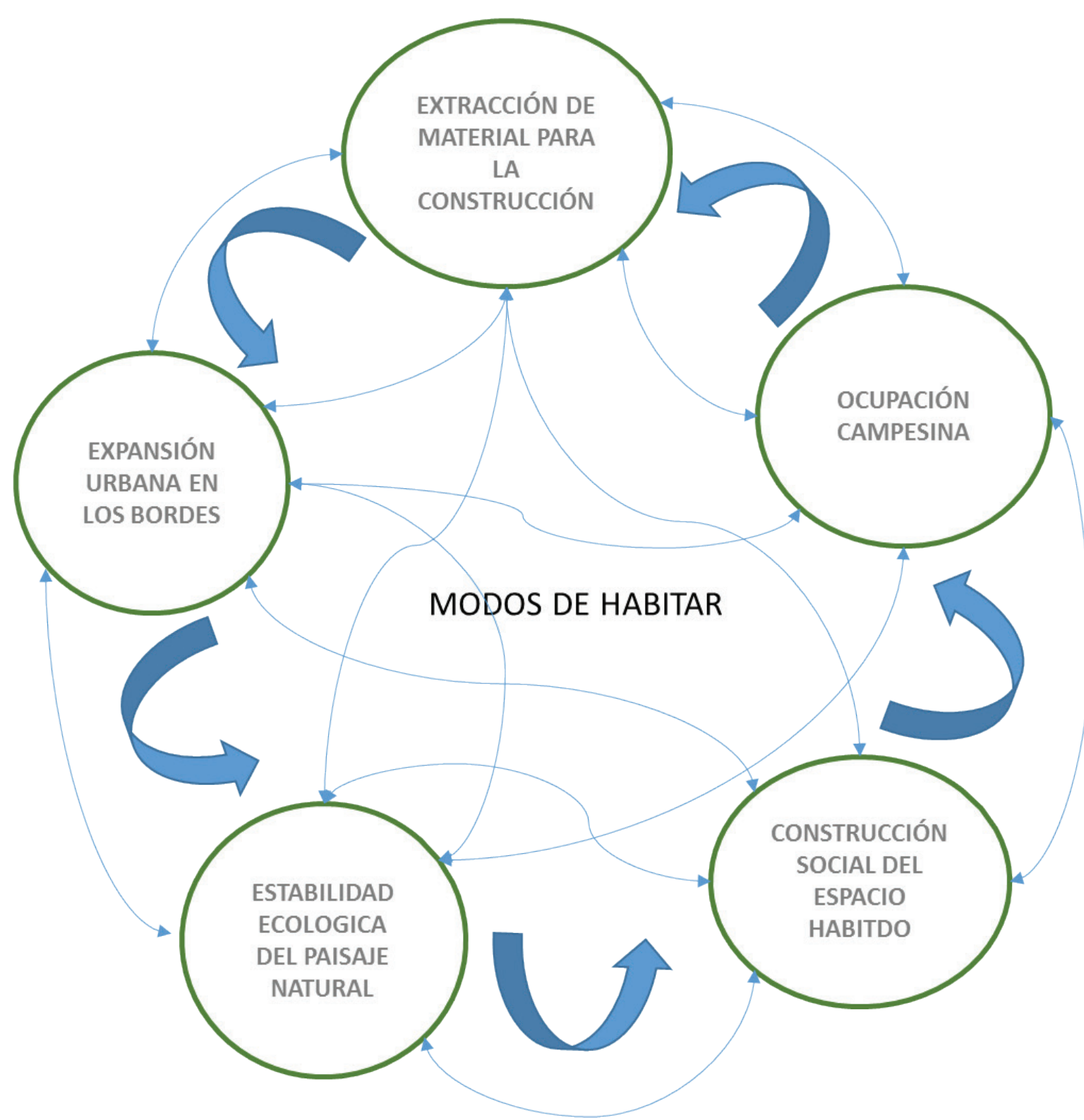

Para efectos explicativos del diseño de los sub modelos en el software STELLA $®$, y basados en el hecho de que todos los subsistemas fueron configurados bajo la misma metodología, a continuación se presentará el subsistema "ocupación campesina", fenómeno que decrecerá o crecerá según el comportamiento de las variables que se asocien a él (figura 11).

\begin{tabular}{|c|c|}
\hline $\begin{array}{l}\text { FACTORES QUE INFLUYEN EN LA OCUPACIÓN } \\
\text { CAMPESINA }\end{array}$ & PERSPECTIVA EN EL SUBSISTEMA \\
\hline Comunidades Rural & \multirow{3}{*}{$\begin{array}{l}\text { Estructura: Componentes físicos del proceso (materia, } \\
\text { sustancia, elementos que constituyen el proceso) }\end{array}$} \\
\hline Comunidad Urbana de borde & \\
\hline Entidades públicas de planeación & \\
\hline Regulación en el precio de la tierra & \multirow{3}{*}{$\begin{array}{c}\text { Organización: fenómeno que afecta el sistema } \\
\text { (vínculos, conexiones, configuración particular entre los } \\
\text { componentes) }\end{array}$} \\
\hline Actividades agropecuarias actuales & \\
\hline Establecimiento de áreas para la protección & \\
\hline $\begin{array}{l}\text { Ocupación minera en áreas rurales } \\
\text { Falta de oportunidades para el desarrollo rural integral }\end{array}$ & \multirow[t]{2}{*}{ Influye en la disminución del evento } \\
\hline Bienestar de las comunidades que cohabitan & \\
\hline Promoción de la cultura campesina & \multirow[t]{2}{*}{ Influye en el aumento del evento } \\
\hline equidad & \\
\hline
\end{tabular}

El modelo bajo el cual está diseñado este subsistema es el modelo logístico, caracterizado por un crecimiento y decrecimiento del evento o fenómeno identificado (ocupación campesina); es decir, al crear conexiones y flujos generados entre los factores registrados en la figura 11, la ocupación campesina decrecerá o crecerá, según el comportamiento de las variables que se asocien a él.

En la figura 12 se presenta su diseño en el programa Stella, donde la situación principal (ocupación campesina) es el proceso central del diagrama; y de allí se desprenden dos flujos o reguladores: uno de entrada y uno de salida, donde el primero regula los datos que aportan al crecimiento de la ocupación campesina, y el segundo regula los datos que aportan al decrecimiento de esta. 


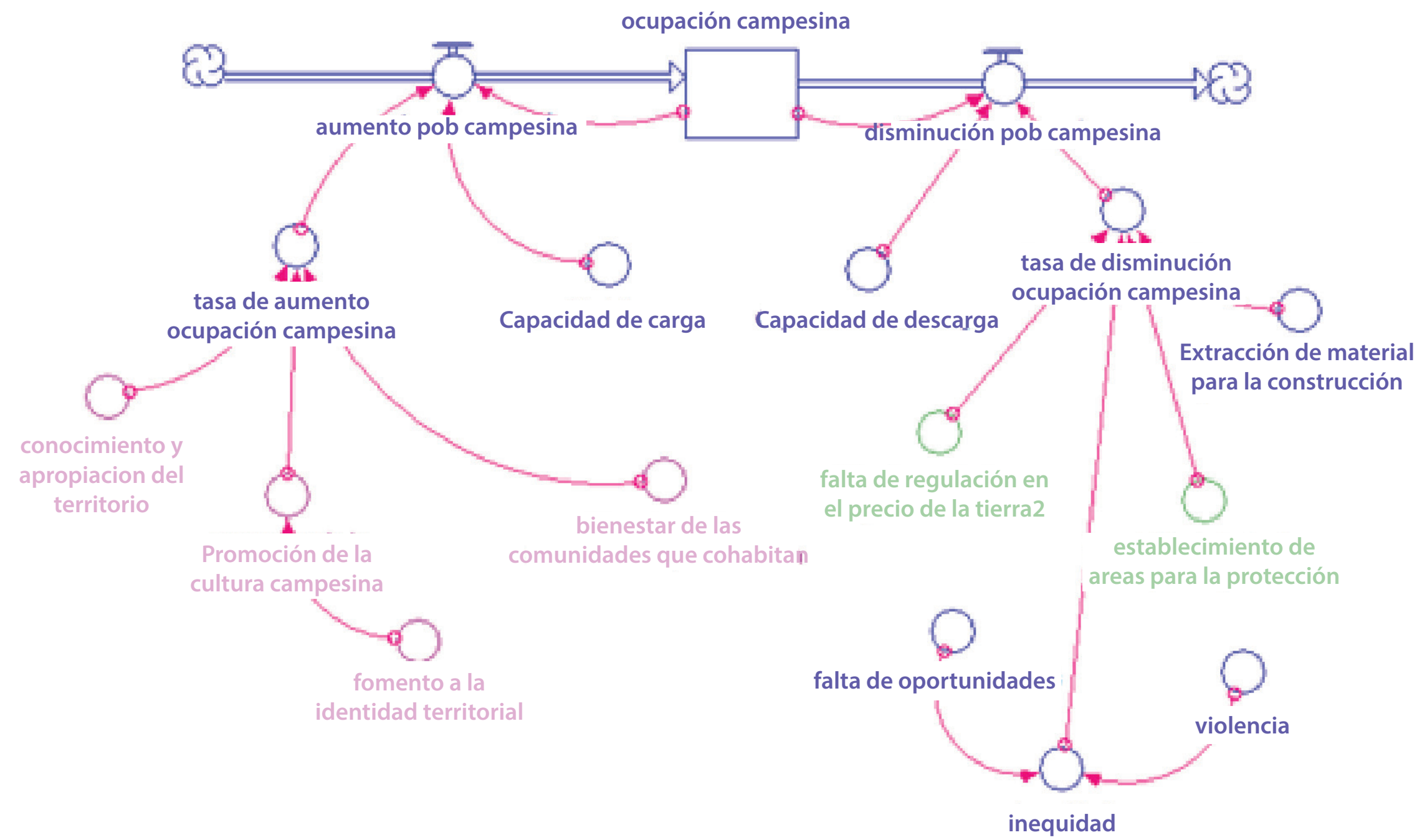

A

Figura 12. Subsistema ocupación campesina en Stella®. Elaboración propia.

Figura 13. Gráfica de tendencia del Subsistema ocupación campesina en Stella® (elaboración propia).
Teniendo en cuenta que las relaciones entre el crecimiento y el decrecimiento están directamente conectadas a la situación "ocupación campesina", la tasa que se encuentre numéricamente más alta que la otra hace que el comportamiento del evento aumente o disminuya. Por ejemplo, si los valores incorporados a la variable violencia son levemente mayores, se registrará una tendencia de reducción en la gráfica asociada a este subsistema (ver figura 13).

\section{1: ocupación campesina}

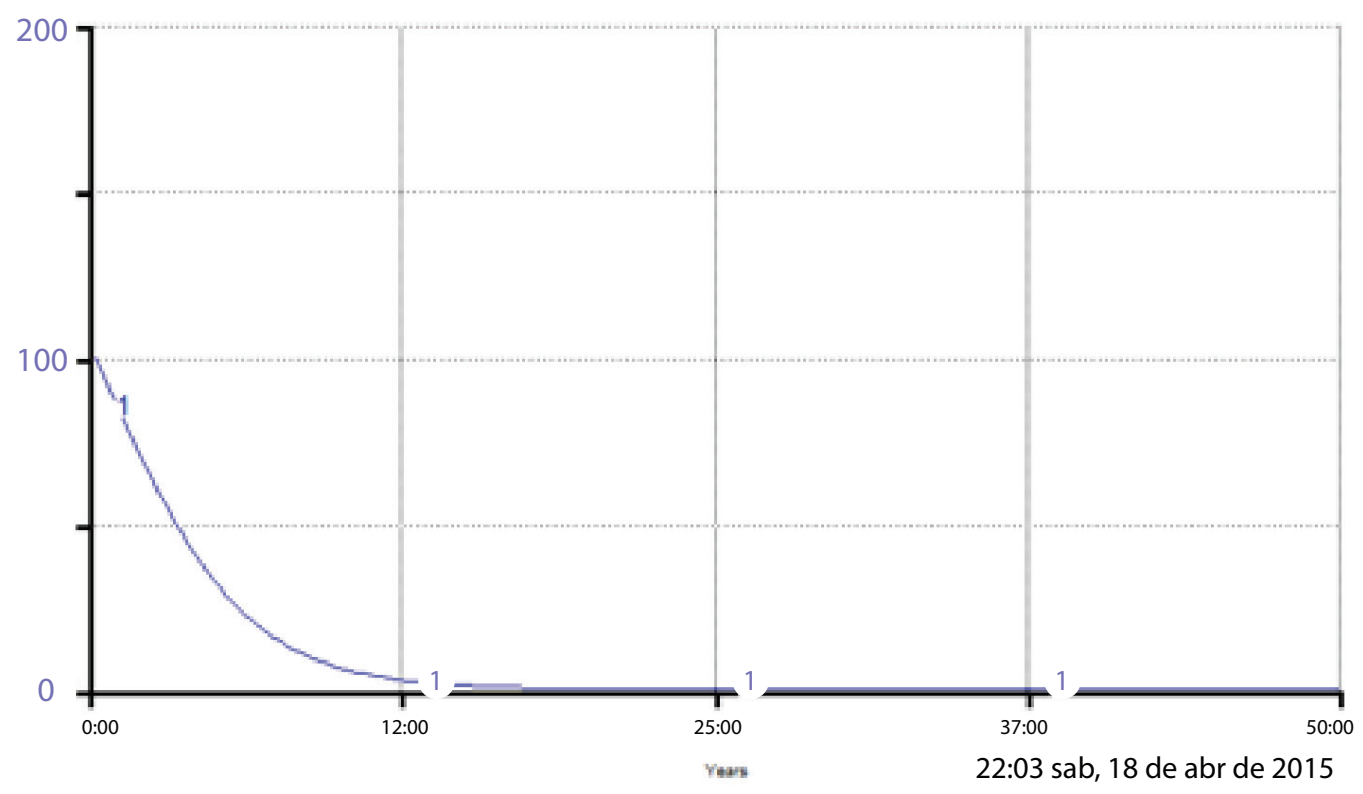

Por lo tanto, cada acción cuantificada, en cualquiera de las situaciones modeladas, determinará el comportamiento final del sistema. Es así como bajo el registro de gráficas de tendencia (que pueden ser integradas) es posible identificar las diversas formas adaptativas que tiene un territorio según las acciones implementadas en él.

\section{Resultados y Análisis}

Teniendo en cuenta lo dispendioso que sería explicar cada uno de los subsistemas, a continuación se enlistarán los esquemas que orientaron las distintas relaciones modeladas (gráficas de tendencia), que serán explicadas en este capítulo, y que fueron definitivos para comprender la situación sistémicamente; para ello, fue necesario retomar los eventos de la figura 10 como las grandes unidades que fundamentan la construcción del modelo y que al final revelan en cinco hechos los modos de habitar más distintivos de Quiba-Arborizadora. 
Figura 14. (a)(b)(c) Subsistemas modelados en el programa Stella ®. Elaboración propia.
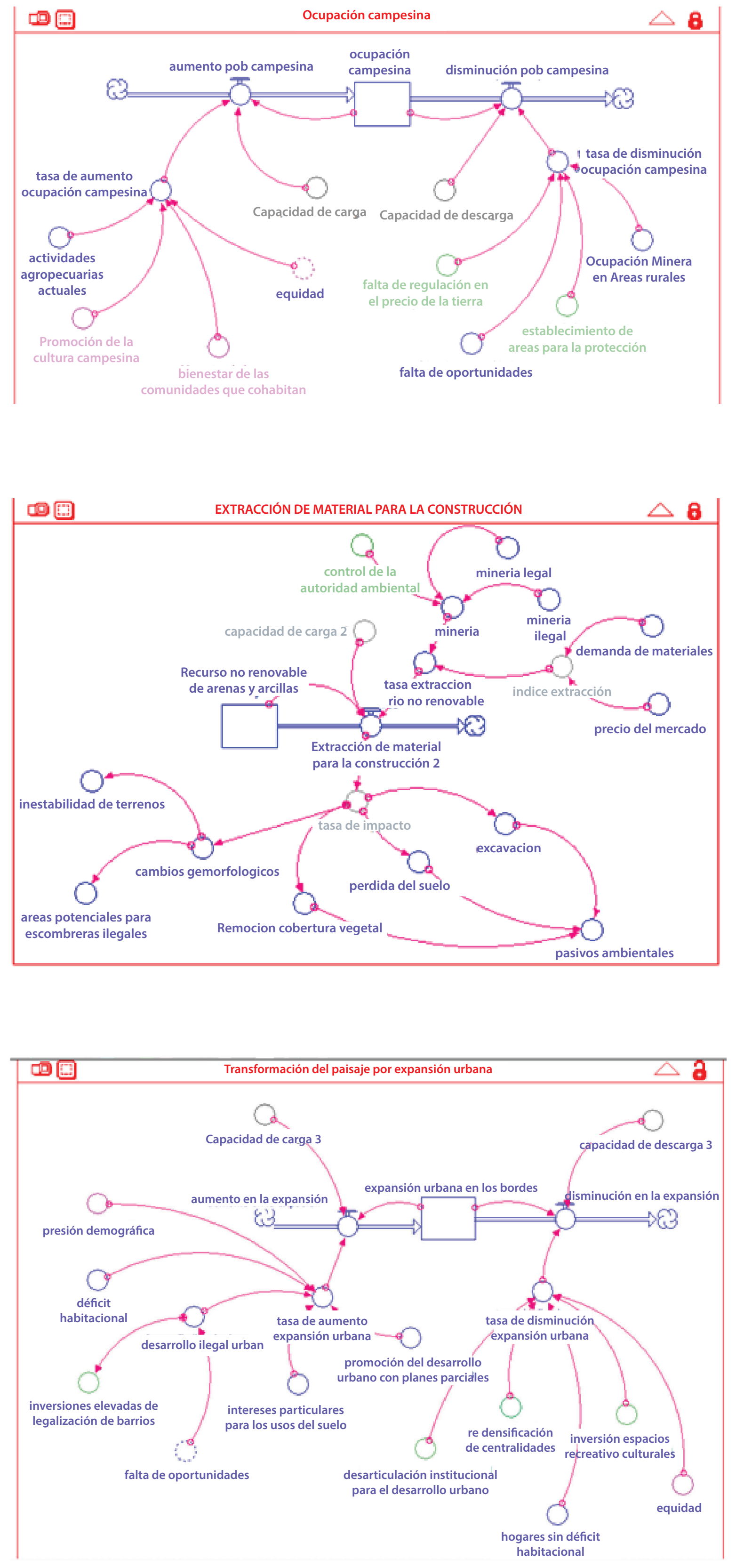
Figura 14. (d)(e) Subsistemas modelados en el programa Stella $®$ (elaboración propia).
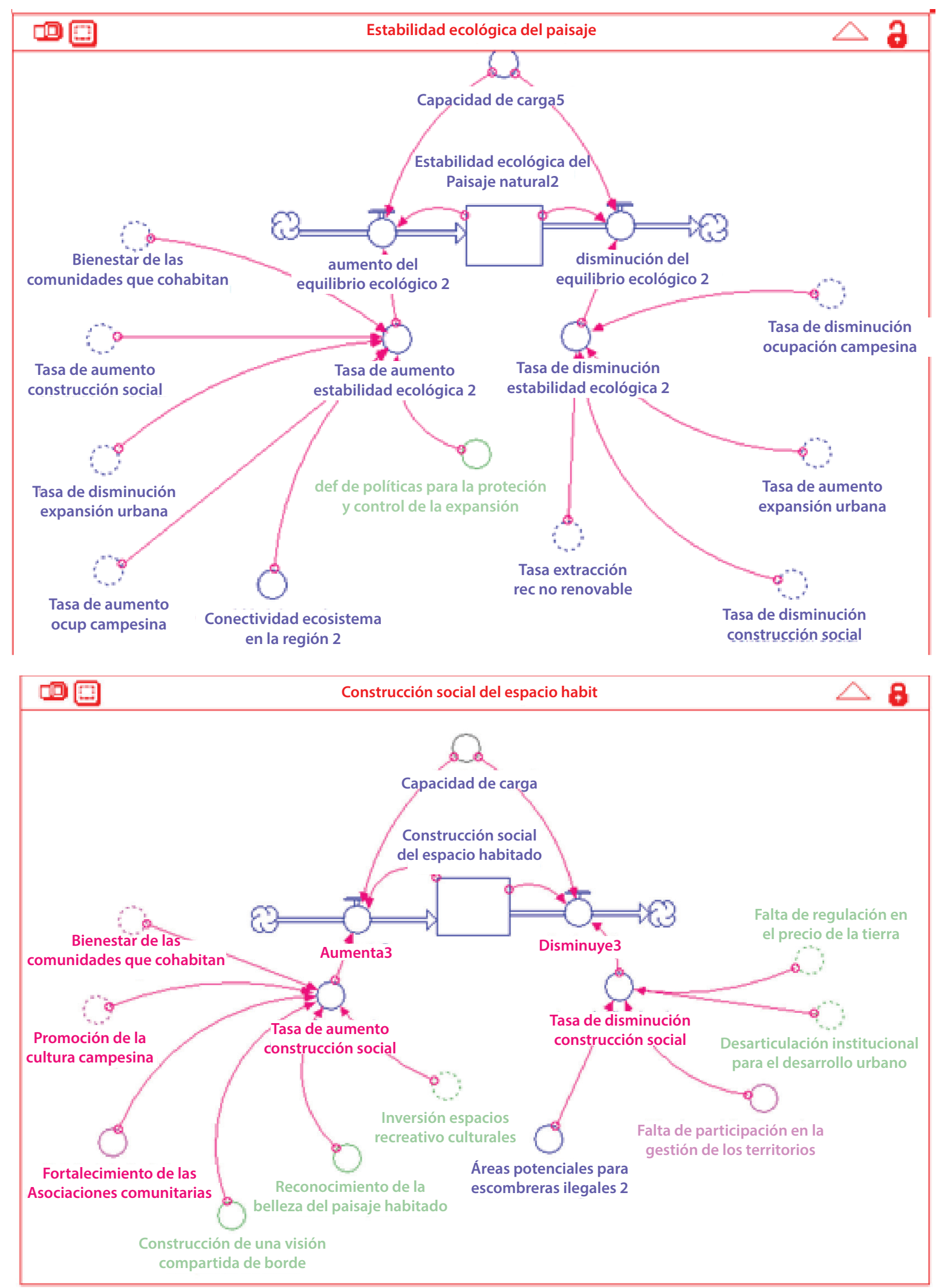

De estos subsistemas, es importante reconocer que sus componentes no son exclusivos, es decir, hay variables que interfieren en otro subsistema (por ejemplo, "inversión espacios recreativos culturales"). Al integrar las gráficas de tendencia de cada subsistema se obtiene:
Figura 15. Registro de la Condición Actual de Sistema. Elaboración propia.

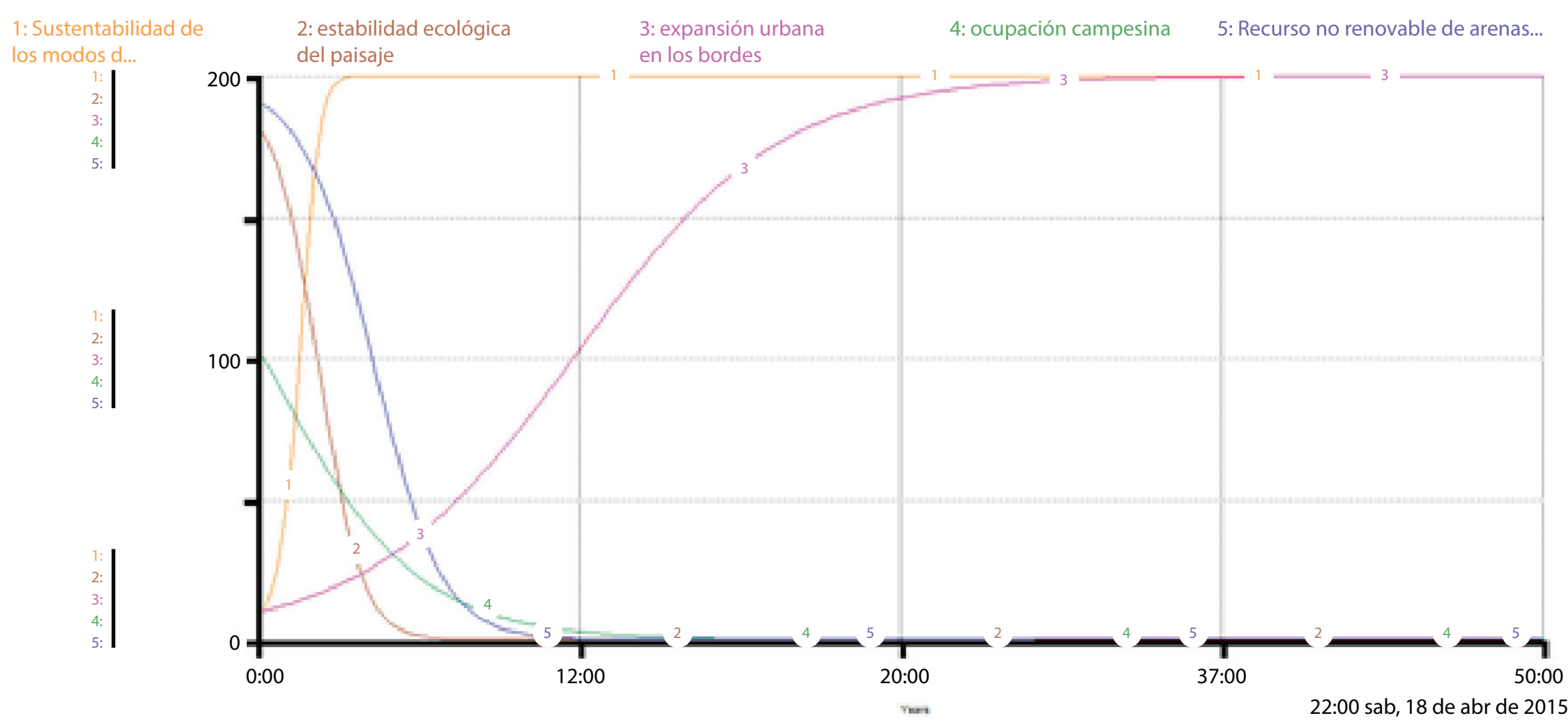


Mientras la estabilidad ecológica (2), la ocupación campesina (4) y el material disponible para la explotación de gravas y arcillas (5) decrecen en los próximos 15 años (valor interpolado del eje de la gráfica), la expansión urbana en los bordes (3) tiende al crecimiento (figura 15).

En el caso hipotético de aumentar los valores en variables como "inversión en espacios que propicien el encuentro en los bordes", "la conciencia colectiva al habitar", "el fortalecimiento de las asociaciones comunitarias" y el "reconocimiento de la belleza paisajística del paisaje habitado", se puede evidenciar, tal y como se muestra en la figura 16, que se podría modificar la tendencia en Quiba-Arborizadora.

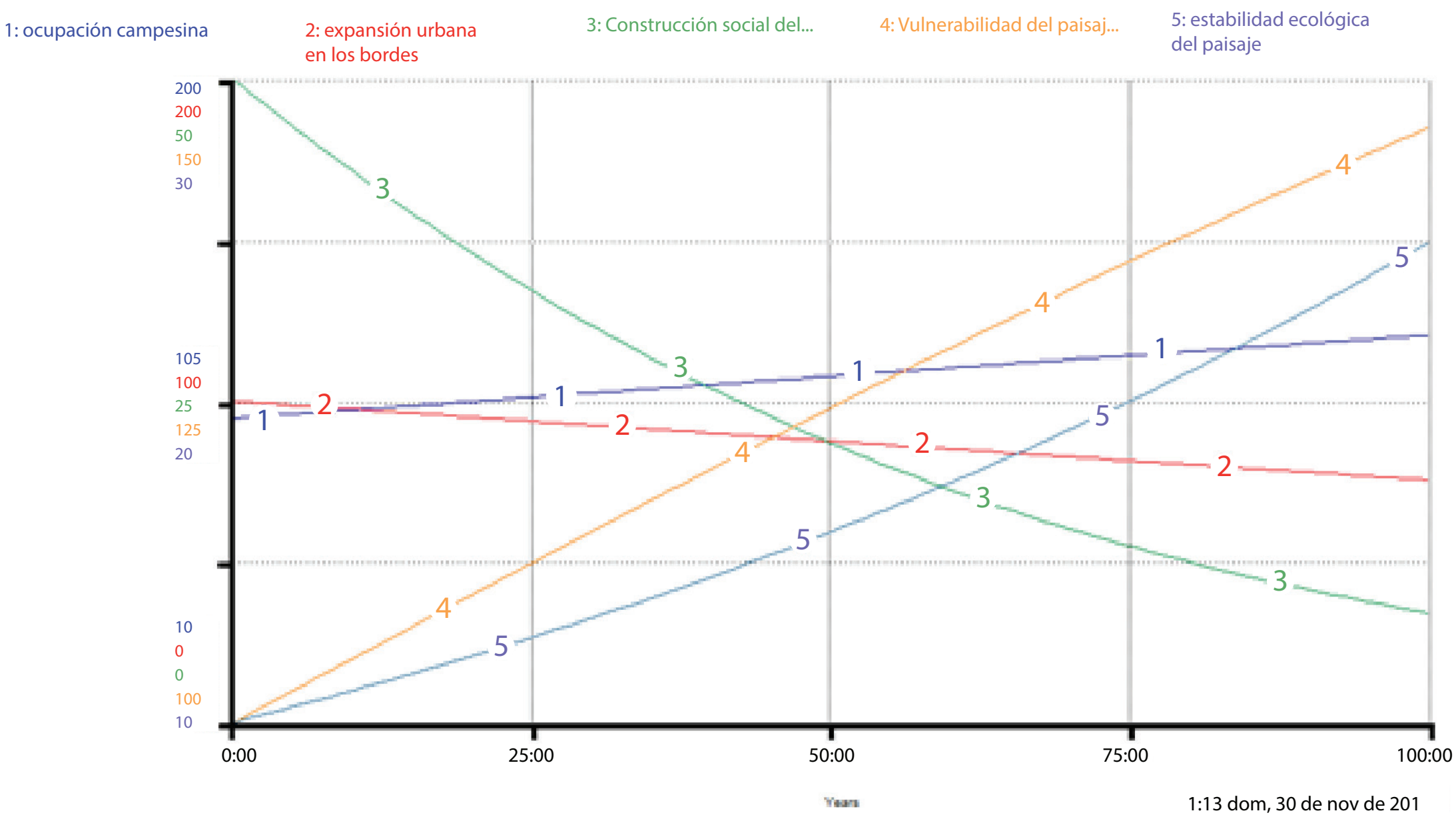

A

Figura 16. Registro del sistema al cuantificar acciones emergentes identificadas. Elaboración propia.

COMPARATIVO GLOBAL SUBSISTEMAS

El cambio de tendencia del sistema en general es bastante notorio, pues el modelo relaciona proporcionalmente cualquier alteración en los valores de referencia asociados a los elementos que lo componen (tanto positiva como negativamente), generando un impacto directo en el aumento o disminución de la estabilidad ecológica del paisaje y en el subsistema de los modos de habitar, pues es sobre todo en estos dos subsistemas donde confluye la mayoría de los componentes del modelo en general.

El procedimiento descrito anteriormente fue ejecutado muchas veces, y en todas las simulaciones se destaca que las acciones que contrarrestan de manera más contundente el estado poco sostenible del sistema actual son: (i) la participación ciudadana y (ii) el reconocimiento de su territorio en los procesos de construcción y planificación del hábitat. Esto apunta a que las posibles alternativas para la sostenibilidad en los bordes estén orientadas más que al cambio de su "estructura" a la reforma en "la organización de los actores que allí intervienen"; es decir, es necesario atender ese conjunto de relaciones creadas entre los componentes que caracterizan el sistema de Quiba-Arborizadora, pues son ellas las que al final más determinan su condición actual y evolución. Esto implica destacar aquellos vínculos entre las comunidades ecológicas y las humanas que allí se desarrollan, pues ambos son sistemas vivos que revelan los mismos principios básicos de la organización.

Teniendo en cuenta, entonces, que en la modelación el reconocimiento del territorio es tan influyente de manera positiva en el sistema luego de varias simulaciones, se destacan como alternativas emergentes para la construcción futura de hábitats sustentables en los bordes de ciudad: 
- Construcción de una visión compartida en el borde.

La zona de Quiba-Arborizadora ha sido construida bajo un espacio geográfico con particulares connotaciones ambientales, lo cual puede ser utilizado para fortalecer el sentimiento de apropiación a dicho territorio, pues finalmente son las significaciones y prácticas sobre los espacios que se habitan los que permiten crear en la población sentidos y sensibilidades que los alienten a participar y a cuidar su entorno. Este simbolismo, de coexistir con otros (entendiendo al "otro" como cualquier ser vivo del entorno) y tratar de manejar unas buenas relaciones de vecindad, no sólo con las comunidades que habitan, sino también con su medio, es aceptar la diversidad, es reconocer que todos tienen el derecho a ocupar un espacio, es sembrar el respeto en las comunidades humanas por la diferencia y esto, a la larga, va consolidando modos de habitar favorables para todas las partes, pues poco a poco la trama de relaciones se va construyendo bajo el respeto por la vida misma y va surgiendo también "reglas de comportamiento" que son aceptadas fácilmente por la colectividad, haciendo más llevadero vivir (De Certeau, 1986).

\section{- Fortalecimiento de las Asociaciones Comunitarias.}

La cooperación siempre revitaliza los vínculos de una sociedad. Por tanto, adelantar acciones que animen la consolidación de alianzas entre los actores que intervienen en la planificación y construcción de este territorio de borde (comunidad, institución, academia) es fortalecer la importancia de las partes en el todo.

Para la zona de estudio no se desconoce el esfuerzo de la mayoría de los líderes en consolidar sus organizaciones, pero se pensaría que el ejercicio más efectivo sería centralizar tantas iniciativas difusas de participación, tanto en los barrios, como en las veredas del sector de estudio. Pero, tal vez, el ejercicio deba ir más allá de la simple reunión de todas las organizaciones. El reto es poder ver en los otros puntos de convergencia que sumen y no seguir enfatizando en aquello que divide; es promover una cultura de respeto a la diferencia, pero con el objetivo común de buscar el bienestar para todos.

Cuando las comunidades se asocian, cada parte va comprendiendo mejor a través del tiempo las necesidades de los demás, identificándose así que el bienestar propio dependerá siempre del colectivo, por lo que vale la pena continuar en el proceso.

Cualquier alternativa que se plantee a los modos de habitar actuales en QuibaArborizadora debe incorporar, ante todo, un cambio en la mentalidad, pues la falta de sostenibilidad de este territorio en sí no es solo un tema de explotación o destrucción de recursos, sino un problema de la forma en cómo se ha reconocido este lugar (como zonas de exclusión y marginalidad) y por ende, ha promovido una forma de actuar entre sus mismos habitantes.

El desafío entonces es de-construir estructuras de pensamiento tan arraigadas, para luego reconstruirlas, orientándolas a una relación ser humano-entorno natural diferente. El cambio propuesto debe implicar un mayor esfuerzo por comprender necesidades, ilusiones, anhelos; es decir, aquellos fenómenos propios de esta zona tan particular, sin orientar la atención en uno específico; evitar el reduccionismo de soluciones bajo el análisis separado de lo económico, lo social, o lo ambiental; en fin, dejar de pensar que la solución a todos los problemas en este borde es una única solución, y es ahí donde siempre quedará alguien inconforme. El objetivo es no dejar de lado todas aquellas posibilidades de correlación entre "lo uno" con "el todo".

Por tanto, el reto es intervenir con acciones que motiven la participación de las comunidades en actividades culturales alternas que promuevan el interés por mejorar su entorno común; es decir, que con el apoyo de las instituciones y la academia se establezcan ciclos de programación cultural que involucren caminatas, actividades lúdicas al aire libre, etc., que promuevan en los habitantes el reconocimiento de los atractivos físicos que ofrece la zona de Quiba-Arborizadora. Por ejemplo, las bellas panorámicas que ofrece de la ciudad (en los atardeceres, por ejemplo), que no existen en otro lugar y que se pueden disfrutar libremente, y que son para todos sus habitantes sin distinción alguna. 
- El reconocimiento de la belleza del paisaje habitado.

Es indisoluble la relación entre el espacio habitado y la calidad de vida de los seres que lo habitan; de hecho, esta relación puede usarse para medir el bienestar. Pero hablar de calidad de vida humana depende, asimismo, de la calidad de vida de los demás seres que habitan la tierra, pues, finalmente, la sensación de bienestar para los seres humanos depende de las condiciones propias del entorno; en otras palabras, si el entorno es armonioso y mantiene un equilibrio dinámico, propio de los estados naturales, el ser humano manifiesta estados de equilibrio emocional y placidez. Esta condición permite plantear que la armonía que se experimente de manera personal sobre un espacio es tan importante como aquellas otras demandas de mejora en las condiciones de la infraestructura, en pro de mejorar "la calidad de vida".

El derecho a un paisaje agradable no puede considerarse, entonces, como una necesidad secundaria de los habitantes de Quiba-Arborizadora, pues, si para estas comunidades de borde es importante conservar los espacios verdes y abiertos que aún mantiene el sector, quiere decir que existe un deseo genuino de contar en su territorio con espacios agradables a los sentidos, que al final se traducen en áreas que ofrecen un sano esparcimiento. Por tanto, la belleza de paisaje pasa a ser entonces de gran importancia para contribuir a la calidad de vida de los habitantes del sector.

Al ser el paisaje el elemento donde se cimientan las re-significaciones de su propio habitar, reconocer un espacio estéticamente agradable reconfigurará sus percepciones y sentidos de apropiación, inspirando así conductas llenas de orgullo a pertenecer a un espacio de reconocida belleza, que los impulsará día a día a mantener y mejorar su entorno.

Por tanto, reconocer en el paisaje aquellos efectos emocionales que produce la apropiación de un espacio es desde donde se establecen comportamientos, intereses y propósitos comunes que se van transformando en intencionalidades colectivas de cuidado y protección, inducidos por el sentimiento que se tiene hacia su entorno.

Sin embargo, dichos patrones no dependen exclusivamente de la estética del paisaje; son muy subjetivos, pues cada quien tiene su propia idea de belleza según su contexto e historia, pero bajo sentidos de apropiación profundos y consistentes con sus significaciones y prácticas, con sus sentidos y sensibilidades, con sus gustos y goces. Se crearán lazos firmes que contribuirán a su viabilidad como sistema habitado, es decir, no es un asunto de valoración estética subjetiva, sino del grado de apropiación estética de la población hacia su entorno.

En este sentido, por los servicios ambientales y ecosistémicos que ofrece la zona de Quiba-Arborizadora, las autoridades ambientales deberían promover figuras de gestión que contribuyan a la conservación y restauración de estos espacios naturales altamente afectados por procesos antrópicos, pues conservar la belleza estética de los bordes de ciudad es una necesidad para impulsar el bienestar conjunto, pues la significación de las montañas escarpadas por procesos de minería es muy diferente a la percepción que se tiene de aquellas montañas de la ciudad que aún guardan su estructura natural.

\section{- Promoción de espacios físicos de encuentro.}

Pensando en robustecer los tejidos sociales a partir del fortalecimiento de las actividades culturales en Quiba-Arborizadora, se propone recrear ambientes físicos deportivos, culturales y recreativos, pero no cerrados ni aislados; por el contrario, si se espera modificar hábitos y costumbres actuales, es necesario contar con espacios que se disfruten abiertamente con los cinco sentidos. Estos espacios deberán ser accesibles tanto para los barrios consolidados en este borde de Bogotá como para las comunidades rurales. La finalidad es poder crear una identidad de las comunidades de borde tan fuerte que les permita mantener en el tiempo los procesos de construcción de su hábitat $\mathrm{y}$, tal vez, esto se logre al reconocer en el territorio elementos propios y oportunidades de desarrollo personal, y por ende también colectivas.

En este sentido el sector de Quiba-Arborizadora ofrece todas las condiciones idóneas, pues al ser la zona libre más extensa del sector, se podría realizar la mayor cantidad de actividades lúdicas al aire libre. Este tipo de actividades que emergen espontáneamente, va fortaleciendo los sentidos de apropiación de las comunidades hacia su territorio, 
precisamente porque son promovidas desde los mismos habitantes y tienen su origen en las mismas relaciones de cotidianidad entre los diferentes grupos humanos y su entorno, lo que permite ir modelando formas alternas y sustentables de habitar el espacio físico de borde.

Pero para que esto se manifieste de manera gradual y progresiva, es necesario fortalecer las interrelaciones entre las comunidades urbanas y rurales de Quiba-Arborizadora, para propiciar una zona de encuentro; por ejemplo, la promoción de bazares, donde las comunidades puedan ofrecer sus productos (ya sean culinarios 0 artesanales) en torno a eventos públicos, donde también se promocionen actos culturales propios de sus habitantes.

Con el tiempo, estos tejidos sociales irán desarrollando ciertos niveles de confianza que serán los que determinen la calidad de vida en estas zonas de borde; en otras palabras, esos vínculos que se crean con los otros evidencian realidades espacio-temporales específicas que van creando identidad y sentido de pertenencia, pues cuando se habita se vinculan lugares con momentos específicos, que son los que finalmente van tejiendo la vida misma. De Certeau (1986, p.43) desarrolla el concepto de la apropiación del espacio con el tema del "Barrio", identificándolo como ese territorio de transición entre lo público y lo privado donde se establecen relaciones de confianza con los otros; es decir, esa prolongación del "habitáculo", donde el habitante siente que forma parte de un entorno social, pues es finalmente el barrio esa parte familiar del espacio urbano en el que se desarrolla el sujeto. En este sentido, la propuesta es fortalecer ese sentimiento de pertenencia y fraternidad en el sector Quiba-Arborizadora, pues en la zona no existe otro lugar con tanta área verde natural que permita la contemplación.

Promover zonas de encuentro, armoniosas, apacibles y naturales, entre lo urbano y lo rural, fortalecerá la co-responsabilidad en el desarrollo del territorio ocupado, pues bajo estrategias cívicas que contribuyan a la cohesión social se irá creando identidad en esta franja de borde y sus espacios públicos se harán vitales para el encuentro, siendo un potenciador de nuevas oportunidades de inclusión y del fortalecimiento del tejido social.

\section{Conclusiones}

- Es importante indicar que con el diseño y conceptualización de este modelo en el programa Stella ${ }^{\circledR}$ se contribuyó notablemente a la comprensión global de la situación de borde en Quiba-Arborizadora, pues permitió plantear, bajo un enfoque sistémico, el estado actual y las posibilidades de cambio en esta zona de borde, a partir de las relaciones y flujos generados entre los componentes identificados a lo largo de esta investigación.

- Con el modelo construido, y bajo la aplicación de diversas simulaciones, se pudo identificar claramente la tendencia de cambio en todo el sistema, sobre todo con la modificación de aquellas variables que se relacionan con la participación ciudadana y el reconocimiento del territorio, por lo que con esta herramienta y las repetidas visitas al área de estudio fue posible sintetizar los productos de la modelación en las alternativas emergentes indicadas en el capítulo anterior que, sin duda, no son las únicas estrategias para mejorar la calidad de vida en los bordes de ciudad, pero seguramente a mediano plazo abonarán firmemente el terreno para fortalecer los instrumentos de participación ciudadana en la gestión y planificación de sus propios territorios.

- En áreas tan dinámicas y difusas como los bordes, es necesario construir puentes de comunicación; escenarios de interlocución que conduzcan a fortalecer la capacidad auto organizativa local. Por tanto, el reconocimiento del territorio como un elemento de identidad, se plantea como alternativa para comunidades tan heterogéneas como estas. El cambio de visión de lo que se considera marginal es fundamental; adoptar una perspectiva basada en una cohesión social en torno al reconocimiento de su patrimonio local, contribuirá a desarrollar un modelo propio de territorio sustentable.

- Por ello, cada uno de los componentes que integran la zona de estudio, debe dejar de analizarse como mundos aislados y desarticulados, pues cada uno de 
ellos forma parte del sistema de borde de la ciudad, y como tal, participa en su promoción y desarrollo, por lo que es necesario incentivar la participación social dentro de los instrumentos de planificación y gestión de los bordes que promueve la administración pública.

- Generar estrategias de ordenación concertada entre la población rural y urbana, promoverá lineamientos de intervención pública y privada mucho más efectivos. Esto implica indiscutiblemente el control de usos de alto impacto como la minería, que actualmente se presenta en el área y que ha contribuido sustancialmente al deterioro físico del sistema de borde, pero no solo el control de alto impacto en términos ambientales, sino también sociales, pues la sostenibilidad que se busca del territorio debería partir de la participación de todos los actores.

Frente a este reto de eco-construcción, se propone que las estrategias estén orientadas a la protección y fortalecimiento de aquellos valores culturales y ambientales que reconocen sus habitantes (tanto del borde urbano como el rural); es decir, adaptar mecanismos para la recuperación y fortalecimiento del arraigo de los que habitan la zona de Quiba-Arborizadora. Esto implica entender que no es solo un área con suelos disponibles para que la ciudad se siga expandiendo; es un área donde confluyen distintas dinámicas que, por su complejidad, difícilmente se podrían categorizar o zonificar estáticamente, y por ello, los procesos que incentiven la participación de sus comunidades (no solo en espacios de discusión o asambleas, sino también en actividades lúdicas y culturales) deben ser permanentes.

- Al hacer partícipes al mayor número de habitantes de la zona en diferentes actividades, habrá un mayor sentido de pertenencia, es decir, se fortalecerá la relación emergente entre naturaleza y la sociedad, una vez se reconozca de manera consciente el espacio vivido. Al fortalecer el sentimiento de corresponsabilidad en el bienestar de sus territorios, podrán emerger diferentes propuestas comunitarias para el mejoramiento de su calidad de vida, pero como un pensamiento colectivo. Así será posible contribuir a la re-definición de los modos de habitar actuales, es decir, a partir de las vocaciones que los mismos habitantes de Quiba-Arborizadora identifican en su territorio se puede llegar a acuerdos que les permitan una mayor sostenibilidad.

El reto es, entonces, construir una visión compartida que involucre a todos los actores $y$, asimismo, sean definidas unas responsabilidades, pero que, sobre todo, logren integrar a los habitantes de la zona rural y de la urbana bajo un objetivo común, y este puede ser el cuido y gestión de un espacio natural y abierto que ofrece este sector. El verdadero desafío será, entonces, coexistir en medio de la diversidad. Pero no solo de la diversidad biológica, sino también la cultural y social, es decir, respetar al otro y reconocerlo como un elemento fundamental para que el sistema en general sea viable y sostenible. No se trata de buscar un modelo pre-existente de gestión que garantice la sustentabilidad en los bordes de ciudad, pues puede que la solución no sea un molde que pueda ser implementado en otro lugar con condiciones similares, sino más bien, la solución esté orientada a reconocer los espacios y comprender las dinámicas que en ellos se suscitan, de manera que se incentive, de forma permanente, la participación de sus habitantes para que la construcción de su propio hábitat sea colectiva y propia, es decir, sostenible.

\section{Referencias bibliográficas}

Ángel, A. (1996). El Reto de la Vida: Ecosistema y Cultura. Bogotá: Ecofondo.

Capra, F. (1998). La Trama de la Vida, una Nueva Perspectiva de los sistemas vivos. Barcelona: Anagrama.

Capra, F. (2003). Las Conexiones Ocultas. Implicaciones Sociales Ambientales Económicas y Biológicas de una Nueva Visión del Mundo. Barcelona: Anagrama.

Daza, J. (2006). Orgullosamente Campesinos Bogotanos. Programa Red de Seguridad Alimentaria para Pequeños Productores Agropecuarios de las Localidades Rurales del Distrito Capital. Bogotá: Departamento de Trabajo Social Universidad Nacional. 
De Certeau, M. (1986). La invención de lo Cotidiano. España: Instituto Tecnológico de Estudios Superiores de Occidente.

Echeverría, M. C. (2009). Hábitat, Concepto Campo y Trama de la Vida. Medellín: Universidad Nacional de Medellín.

Forrester, J. (1994). Earning through System Dynamics as Preparation for the 21st Century, Keynote Addresss for System Thinking and Dynamic Modeling Conference. Consultado en Linea: http://www.sysdyn.mit/.

Garciandía, J. A. (2005). Pensar Sistémico. Bogotá: Universidad Javeriana

Leff, E. (1997). SaberAmbiental. texto No. 20. Ponencia de la sexta reunión del programa medio Ambiente UNAM. México: UNAM.

Leff, E. (2004). Racionalidad Ambiental, la Reapropiación Social de la Naturaleza. México: UNAM.

Márquez, G. (2002). Ecología y Cultura: Cambio Ambiental, Evolución Biológica y Evolución Cultural. Politeia, 28, 41-56.

Morlan, I. (2010). Modelo de Dinámica de Sistemas para la Implantación de Tecnologías de la Información en la Gestión Estratégica Universitaria. Donostia San Sebastián: Universidad del País Vasco.

Murillo, R. (2007). Aplicación de la Metodología de Sistema Suave y el Uso de Sistema Viable en la Comunidad Campesina de Laguneta. Bogotá: Universidad de los Andes.

Rivera, David (2014). Documento Técnico De Soporte - Importancia Ambiental De La Cuenca Media Y Baja Del Rio Tunjuelo Y Afectación Por Los Polígonos De Actividad Minera. Secretaria Distrital de Medio Ambiente, contrato de prestación de servicios No. 01323 DE 2013.

Sánchez, J. (2009). El Hábitat no es una Cosa. En Universidad Nacional de Colombia (Ed.), ¿Qué es Hábitat? las preguntas por el hábitat (pp. 117-140). Medellín: Escuela de Hábitat CEHAP. 